\title{
Organizational Citizenship Behavior: It's Importance In Academics
}

Thomas A. Kernodle, Ph.D., Empire State College, Staten Island, USA Deborah Noble, Ph.D., Empire State College, Brooklyn, USA

\begin{abstract}
The purpose of this paper is to support Organizational Citizenship Behavior (OCB) as an essential area of study in the field of business education that is often neglected. OCB has been defined as individual behavior that is discretionary, not directly or explicitly recognized by the formal reward system, and that in the aggregate promotes the effective functioning of the organization (Organ, 1988). The inclusion of OCB in business education could be beneficial to both managers and organizations by educating the manager, as well as by developing employees. $O C B$ is typically discussed in Organizational Behavior $(O B)$ courses; however, it is often a relatively small part of the coursework. There are also several other relevant areas of management that fail to include $O C B$ as part of academic content.
\end{abstract}

Keywords: Organizational Citizenship Behavior; Business Education; Management Education

\section{INTRODUCTION}

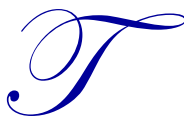

he focus of this paper is to argue that Organizational Citizenship Behavior (OCB) is a useful field of study that should receive more attention in business education. OCB is a relatively new and developing field of study and has received no recognition outside of the context of Organizational Behavior (OB), and only limited recognition within the context of OB. Knowledge of OCB can be useful for the individual employee, line managers, human resource managers, and organizations as a whole. While studies show that employees who exhibit OCBs can contribute to the effectiveness of the organization, the concept has been largely ignored in business education.

\section{What is OCB?}

OCB has been defined "as individual behavior that is discretionary, not directly or explicitly recognized by the formal reward system, and that in the aggregate promotes the effective functioning of the organization" (Organ, 1988 , p. 4). In a very literal sense, an employee who exhibits OCBs is acting as a "citizen" of the organization. This can be translated as an employee going above and beyond the call of duty and doing things that are outside the boundaries of his or her job description. Although there is much disagreement about how OCBs are actually constructed, many researchers agree that the main dimensions of OCB are altruism, courtesy, sportsmanship, civic virtue, and conscientiousness (Noble, 2007; Smith, Organ, \& Near, 1983).

Altruism includes all discretionary behaviors that have the effect of helping a specific other person with an organizationally relevant task or problem. Also known as Helping Behaviors, this dimension can also include actions such as Cheerleading and Peacekeeping (Organ, 1988).

Courtesy is the discretionary enactment of thoughtful and considerate behaviors that prevents work-related problems for others (Ehtiyar, Aktaş Alan, \& Ömüriş, 2010). It includes such actions as "touching base" with those parties whose work would be affected by one's decisions or commitments.

Sportsmanship, in relation to OCB, is an employee's ability to cope with the inconveniences of the workplace without complaining verbally or formally. Podsakoff, Mackenzie, Paine, and Bachrach (2000) stated that 
"good sports are people who not only do not complain when they are inconvenienced by others, but also maintain a positive attitude even when things do not go their way, are not offended when others do not follow their suggestions, are willing to sacrifice their personal interest for the good of the work group, and do not take the rejection of their ideas personally" (p. 517).

Civic Virtue can be defined as "the responsible participation in the political process of the organization" (Schnake \& Dumler, 2003, p. 284). Participating in organizational events, attending meetings, vocalizing opinions, reading internal mail, talking about work issues on personal time, and becoming involved in organizational issues would be considered Civic Virtue.

Conscientiousness, also known as Individual Initiative, is an employee being proactive in taking on responsibilities and performing tasks that are not necessarily required. Organ (1990) defines it as "a pattern of going well beyond minimally required levels of attendance, punctuality, housekeeping, conserving resources, and related matters of internal maintenance" (p. 96). Individual Initiative has also been labeled as persisting with enthusiasm and extra effort and volunteering to carry out task activities (Borman \& Motowidlo, 1993).

\section{Who Cares?}

There are two distinct ways that OCBs could be beneficial to managers and organizations. The first way is through education of the manager. Empirical evidence shows that there is a significant relationship between an individual's level of education and the amount of OCBs that are exhibited by the individual (Noble, 2006). Employees who do not possess a college degree are more likely to display OCBs than those with an associate's, bachelor's, or master's degree. There are many possible implications to these findings. It can be deduced that business students are not learning the importance of OCBs at the undergraduate and graduate level.

One of the primary goals of business schools is to prepare students to meet the challenges of an everchanging business environment and to prepare them for successful careers in the industry. One way is to ensure they have and are using key skills, such as OCBs (Allison, Voss, \& Dryer, 2001). By developing managers that are aware of OCBs and can exhibit the necessary skills to become a citizen of the organization, business schools can deploy managers that can add more value to their organizations.

The second way is through employees. OCB is of great importance to managers because they can use the concepts and the findings in OCB studies to help them better manage employees. As a result, if a manager could inspire employees to exhibit OCBs, it could lead to improving the job performance of the employee, the effectiveness of the group the employee belongs to, as well as the overall effectiveness of the organization as a whole.

Studies have shown that employees who exhibit OCBs are more likely to have higher productivity and receive higher performance appraisals (Noble, 2006). Studies have also shown that employees who have a better relationship with their supervisor are more likely to exhibit OCBs and as a result, are more likely to have a higher work performance (Kernodle, 2007).

This individual performance can be aggregated to the group level. If an employee displays a higher performance at the individual level, there is a strong chance that the group the employee is a member of will also have a higher performance. An employee's job performance, as well as a group's performance can help increase an organization's overall effectiveness (Organ, 1988; Schnake \& Dumler, 2003).

\section{OCB in Business Education}

OCB is a topic that is covered in most $\mathrm{OB}$ textbooks and is occasionally taught in OB classes. OCB is rightfully a part of OB because it deals with the behavior of employees. It is, however, a relatively small part of the coursework when compared to other topics in OB. Because of its importance to managers, there should be more emphasis on the behavior of employees as citizens. 
Many OB courses and textbooks are segmented into 3 main sections: individual factors, group factors, and organizational factors. When OCB is incorporated into the course material, it is often covered as part of the individual behavioral factors. More specifically, OCB is taught as a part of individual job attitudes. According to Robbins and Judge (2010), "job attitudes are evaluative statements - either favorable or unfavorable - about objects, people, or events" (p. 47). One of the most important job attitudes in OB is job satisfaction, which is defined as "a positive feeling about the job resulting from an evaluation of its characteristics" (Robbins \& Judge, p. 51). It is believed that OCB is an outcome of high job satisfaction, and satisfaction influences OCB through perceptions of fairness. The more satisfied an employee is with his or her job, the more likely he or she will be to exhibit OCBs. (Robbins \& Judge, 2010)

There are areas of individual behavior, other than job attitudes, where OCB could be a legitimate academic topic. Another major individual behavioral factor is personality. Robbins and Judge (2010) define personality as "the sum total of ways in which an individual reacts and interacts with others, the measurable traits a person exhibits." (p. 15). Different types of personalities may be more likely to exhibit different dimensions of OCB. It would be beneficial for students to learn which personalities may act as predictors to OCBs. Managers may find this information useful when selecting employees for a particular job or task by trying to make the right fit for a particular position.

One of the more important individual factors in $\mathrm{OB}$ is motivation. There is a relationship between motivation and OCB (Finkelstein, 2011; Barbuto \& Story, 2011), which is rarely discussed in OB texts or literature. Different types of motivation can be associated with OCB. It would be beneficial for managers and business students to know of these relationships in order to lead employees in the workplace.

While OCB is generally an individual behavior, it does have an impact on other factors. OCB could be incorporated into various group factors as well. Two of the more important group factors are teamwork and leadership. Individual behaviors could be aggregated to the group level. If two members of a team exhibit different amounts of OCBs, the cohesiveness, as well as the overall group performance could be affected. Although individuals are leaders, the topic of leadership is often a group factor because a leader needs followers. Studies have shown a positive relationship between Leader-Member Exchange (LMX), which is the relationship a leader has with his or her subordinate, and the amount of OCBs that subordinate exhibits (Kernodle, 2007). This is an important concept for business students who plan to become managers. If they can be aware and focus on developing and maintaining a strong, positive relationship with their subordinates, there is a greater chance of the subordinates exhibiting OCBs.

Although job performance is generally not an area of study in OB, it arises as part of several other areas, especially job attitudes. Studies show there is a direct link between the amount of OCBs an employee exhibits and their overall performance (Kernodle, 2007). If a manager can get an employee to exhibit OCBs, this could lead to a higher performance by the employee. Individual job performance is related to group performance, as well as the overall performance of the organization.

There are several other areas of management where OCB is often overlooked. Other courses where OCB should receive attention are Principles of Management, Human Resource Management (HRM), Business Ethics, Introduction to Business, Organizational Theory, and Managerial Leadership.

OCB is rarely mentioned in HRM textbooks or classes. HRM courses and texts are often segmented into the major Human Resource (HR) functions such as staffing, training, appraising, compensating, and often an introduction or conclusion comprised of trends, special issues, or international perspectives. OCB could be incorporated into the trends of HR as it could be viewed as a contemporary trend among employees today. OCB may also be taught as part of the staffing section of HRM. Knowledge of OCB could play an important role in selecting individuals in a workforce. When selecting employees, HR managers could not only focus on selecting candidates with the right skill sets who would fit into the organizational culture, but they could also look for candidates who are more likely to exhibit OCBs. OCB could also be covered when teaching about training and development, as HR managers could include OCB as part of the training process. Most HRM courses also have a section on labor-management relations, which deals specifically with labor unions. Studies have shown negative 
relationships between an employee's commitment to their labor union and the amount of OCBs they will exhibit (Kernodle, 2007). The less committed they are to the union, the more likely they will be to exhibit OCBs. It is important for potential managers to know the implications of labor unions and how it can affect employee behavior.

Basic Business Management courses such as Introduction to Business or Principles of Management typically do not cover the concepts of OCB. Introduction to Business, similar to Business Organization and Management, is the most basic business course at the undergraduate level and is often the first business class that a student completes. The course is usually segmented into the major business functions, or fields of study, such as Management, Marketing, Accounting, Finance, and Information Systems, often with a section on current business trends. As with HRM, OCB could be included as one of the current trends in the workforce today. OCB could also be included in the Management portion of the course. Similar to HRM, OCB could be included as part of Leadership or Motivation.

Principles of Management is usually the second course completed as part of an undergraduate business student's curriculum. Other than OB, it is probably the most appropriate course for inclusion of OCB as a topic. Principles of Management is usually segmented into the major managerial functions: planning, organizing, leading, and controlling. OCB could be made part of the organizing function of management by teaching it as part of the HRM function of Management. In addition, it could be included in the Leading function of Management by teaching it as part of the personality portion, the team building portion, or the motivational portion of leadership, as with OB.

Managerial Leadership and Organizational Theory are courses that are occasionally offered at the undergraduate level, as well as at the graduate level. OCB could be included in the material in each of these courses. While some overlap exists between Managerial Leadership and OB, as well as with Principles of Management, the focus of Managerial Leadership is on the leadership style and skills of the manager in order to effectively lead others in the organization. Similar to some of the aforementioned courses, OCB could be linked to motivation, LMX, or organizational culture, which are often common topics of importance in this course. There could also be an emphasis on the concept of leading by example. If managers are effective leaders, lead by example and exhibit, OCBs, their subordinates are more likely to exhibit OCBs. Organizational Theory focuses on how organizations begin, develop, and change over time, with a focus on the internal and external forces that affect them. Two of the major areas in Organizational Theory are organizational culture and organizational development. OCB could be incorporated into the culture portion of the course by focusing on how managers should make OCB a part of the culture of the organization. By fostering a culture where employees exhibit OCBs, this could help improve the overall effectiveness of the organization. OCB could also be included in the development portion of the course. Organizations progress through a life cycle. As they go through different stages, they change and specific needs arise, such as leadership, teamwork, and creativity. OCB could be incorporated into this portion as it may play a role in each different stage of the organizational life cycle.

Business Ethics is a growing field of study in business schools. There is an overlap of OB and Business Ethics and there is literature to support the specific relationship between OCB and ethics. OCB is not, however, included in most Business Ethics courses and is not discussed in many Business Ethics textbooks. The structure of a Business Ethics course varies from school to school, as well as from instructor to instructor. Many Business Ethics courses are segmented into individual factors and organizational factors that affect ethical behavior and decisionmaking. OCBs could be incorporated in either of these parts of the course. As stated earlier, individual factors such as personality, motivation, and job attitudes, are all related to OCBs. Organizational factors such as culture, organizational performance, and HR aspects such as training, could also be related to OCBs.

Many Business Ethics courses and texts use the case analysis approach. This approach involves a case study of a particular organization and an ethical dilemma or issue that it faced. Some common examples are WalMart or Enron. OCB could also be covered as part of various case studies that are being covered. It should also be noted that OCB is not synonymous with ethical behavior. At times, "company employees" have engaged in OCBs that are actually unethical behaviors due to their desire to go above and beyond to help or protect the organization. For example, an employee who makes a fraudulent accounting entry so the company's financial statements look good may be acting as the organization's top citizen. The behavior, however, is unethical. 


\section{CONCLUSION}

OCB is a fairly new and emerging field of study. While it receives limited attention in OB courses, it could and should receive more attention in business education. While it may not be necessary to include OCB in each of the aforementioned courses, OCB should receive more emphasis that it currently receives in academics. Increased attention may help employees thrive in their respective organizations and may help managers lead successful groups, teams, or departments. Finally, it may also help improve the overall effectiveness of the organization.

\section{AUTHOR INFORMATION}

Dr. Thomas Kernodle is an assistant professor at Empire State College in the Staten Island Unit. He received his $\mathrm{Ph} . \mathrm{D}$. in Business Administration from Touro University International, his Master's of Business Administration from Regis University, and his Bachelor's of Science in Business Management from New Jersey City University. E-mail: Thomas.Kernodle@esc.edu (Corresponding author)

Dr. Deborah Noble is an associate professor at Empire State College in the Brooklyn Unit. She received her D.B.A from Argosy University, her Master's of Business Administration from Long Island University, and her Bachelor's of Arts from The College of New Rochelle. E-mail: Deborah.Noble@esc.edu

\section{REFERENCES}

1. Allison, B. J., Voss, R. S., \& Dryer, S. (2001). Student classroom and career success: The role of organizational citizenship behavior. Journal of Education for Business, 76(5), 282-289.

2. Barbuto, J. E., Jr., \& Story, J. S. P. (2011). Work motivation and organizational citizenship behaviors. Journal of Leadership Studies, 5(1), 23-34.

3. Borman, W. C, \& Motowidlo, S. J. (1993). Expanding the criterion domain to include elements of contextual performance. In N. Schmitt \& W. C. Borman (Eds.), Personnel selection (pp. 71-98). San Francisco: Josey-Bass.

4. Ehtiyar, V. R., Aktas Alan, A., \& Ömüriş, E. (2010). The role of organizational citizenship behavior on university student's academic success. Tourism and Hospitality Management, 16(1), 47-61.

5. Finkelstein, M. A. (2011). Intrinsic and extrinsic motivation and organizational citizenship behavior: A functional approach to organizational citizenship behavior. Journal of Psychological Issues in Organizational Culture. 2(1), 19-34.

6. Kernodle, T. A. (2007). Antecedents and consequences of organizational citizenship behavior: A hierarchical linear modeling study. Dissertation Abstracts International, 68(3), 1069A. (UMI No. 3256150)

7. Noble, D. A. (2006). The relationship of formal education and gender to organizational citizenship behaviors. Dissertation Abstracts International 70(2). (UMI No. 3346737)

8. Organ, D. W. (1988). Organizational citizenship behavior: The good soldier syndrome. Lexington, MA: D.C. Heath and Company.

9. Organ, D. W. (1990). The subtle significance of job satisfaction. Clinical laboratory Management Review, 4(1), 94-98.

10. Podsakoff, P. M., Mackenzie, S. B., Paine, J., \& Bachrach, D. (2000). Organizational citizenship behaviors: A critical review of the theoretical and empirical literature and suggestions for future research. Journal of Management, 26(3), 513-563.

11. Robbins, S. P. \& Judge, T. A. (2010). Essentials of Organizational Behavior. (10th ed.). Upper Saddle River, NJ: Pearson Education Inc.

12. Schnake, M. E., \& Dumler, M. P. (2003). Levels of measurement and analysis issues in organizational citizenship behaviour research. Journal of Occupational and Organizational Psychology, 76, 283-301.

13. Smith, C.A., Organ, D. W., \& Near J. P. (1983). Organizational Citizenship Behavior: It's nature and Antecedents. Journal of Applied Psychology 68(4) 653-663. 


\section{$\underline{\text { NOTES }}$}

